\title{
LIFE: BIOGRAPHY AS CONFLICTUAL COHERENCE
}

\author{
ANTHONY J. LA VOPA \\ Department of History, North Carolina State University \\ E-mail: anthony_lavopa@ncsu.edu
}

In the early 1970s, when I was a graduate student, biography was considered "an unloved stepchild" of the historical discipline. The naive empiricism of its soup-to-nuts narratives seemed deaf to any theory that might call the biographer's craft into question. In 2009, the American Historical Review honored the genre of biography with a roundtable on its creative renewal. ${ }^{1}$ Oddly (and regrettably) there was no mention of the work of Jerrold Seigel in any of the roundtable essays, though he had published three innovative biographical works over the previous thirty years. Characterizing Seigel as a biographer by trade would, to be sure, seriously diminish the scope of his scholarship. But two of his seven books have been full biographies, and in two others a biographical approach has been central to his modus operandi. A leading figure in refashioning the genre, he has been quite conscious of the implications of that commitment. In 1987 he ended an article on Durkheim with a challenge: "our knowledge of the human world must be able to survive the recognition of its personal sources." ${ }^{2}$ Three years later he concluded an article on "the personal roots of Foucault's thinking" with another provocation to recent preoccupations in the discipline: "the proclaimed death of the subject is not some newly discovered set of relations that produce the illusion of human will and intentions as residues of their silent operation, but the action of a subjectivity that will not speak its name."3

Seigel's biographical approach has been a steadfast working out of a paradoxical alternative to the death of the subject: there is a discrete and coherent

“AHR Roundtable: Historians and Biography," American Historical Review 114/3 (2009), 573-661.

2 Jerrold Seigel, "Autonomy and Personality in Durkheim," Journal of the History of Ideas 48/3 (1987), 483-507, at 507.

3 Jerrold Seigel, “Avoiding the Subject: A Foucaultian Itinerary," Journal of the History of Ideas 51/2 (1990), 273-99, at 299. 
individual subjectivity, but the coherence lies precisely in a deep structure of psychic tensions, a conflictual unity that in most cases the subject cannot resolve. It is this way of peering into the individual psyche that explains the creative tension in Seigel's practice, and that has generated much of the controversy about it. Clearly Seigel's notion of a deep psychic structure does not appeal to a universal and timeless (i.e. unhistorical) constitution of human nature to explain his subjects' motives. But since the psychic structure is nonetheless so deep, and since it survives so many episodic twists and turns in his narratives, the question arises whether enough wiggling room is left for the freedom of individual agency. And yet there is another side to the paradox: Seigel's biographies demonstrate again and again that that same structure of conflict, precisely because it is historically specific and social in its formation, is the source of the both the creative freedom and the public resonance of major figures in literature and the visual arts. His historical subjects do not lose their individuality, and in some cases their studied eccentricity; and yet they are made representative of collective phenomena, and indeed their individuality is precisely what gives them larger significance for understanding a society and a culture. Seigel's biographical work is so absorbing in part because he is fully aware of these issues, and of the implications of his methodological choices. While insisting that intellectual biography must have a psychological dimension, he repeatedly asks himself and his readers how far a historian committed to rigorous empiricism can take psychological excavation without losing credibility. He has been forthright, even unguarded, in confronting a closely related question: whether one can or should use biography to work through one's own dilemmas in the face of modernity's politics and politics of culture.

I was quick to read Seigel's Marx's Fate: The Shape of a Life when it appeared in 1978 because I was intrigued by the title. Fate and shape were seemingly odd choices. Could a historian assign a "fate" to a historical subject without falling into a hopelessly unhistorical teleology? To give a life a shape, of course, is no more than to speak metaphorically. But does the metaphor leave any space for the contingencies the historian should be intent on finding?

A crucial first step in understanding Seigel's concepts of a life fate and a life shape is to recall that most of the work on Marx's Fate was done in the 1970s. The new social history was in the ascendancy, and its concern was with collective agency; individuals tended to figure in it only to the extent that they could be said to exemplify group behavior. In choosing biography, Seigel was by no means rejecting social history. He was, and has remained, well versed in the subject, as evidenced by his publication of an ambitious synthesis of his thinking about 
bourgeois modernity in 2012. In Marx's Fate and his later biographical works, the social and the psychological are virtually inseparable. We are kept aware that Marx's psychic tensions were shaped by his upbringing as the son of a German Jewish bourgeois lawyer turned Lutheran, and that in his later years he suffered wracking guilt about failing to support his family at an adequate level by bourgeois standards.

Given his commitment to exploring "personal sources," Seigel had to confront psychobiography, which had its followers but was also drawing heavy fire from the discipline's mainstream for being ahistorical or just plain silly. Erik Erikson's Young Man Luther had appeared in 1958 and his Gandhi's Truth in 1969. In 1977, Robert G. L. Waite published The Psychopathic God: Adolf Hitler, which applied concepts from Freudian and post-Freudian clinical psychology to explain Hitler's pathology. Without the insights of Erikson and the British psychiatrist D. W. Winnicott, Seigel would not have been able to use Marx's texts and the way he lived his life to delve as deeply as he did into his psyche, far deeper than most practitioners of intellectual biography would feel justified in doing. But there is a crucial distinction here between psychobiography, understood as the application of clinical concepts, and biography with a strong psychological perspective. One of Seigel's aims was to demonstrate that historians' denial of legitimacy to the one should not be extended to the other. He made quite clear in the introduction to Marx's Fate that he was rejecting psychobiography as it was then being practiced. It was partly a matter of historical empiricism. There was hardly any textual evidence for reconstructing Marx's childhood formation, as opposed to locating his family in the social world of Trier (which he did in considerable detail); his conflicted subjectivity only enters the historical record when he is in his late teens. Seigel had to start with the result of Marx's childhood formation, not with the process itself. But even if there had been abundant evidence from the early years, Seigel would not have psychoanalyzed Marx. What he took from Freudian psychoanalysis and its offshoots were two points of departure for practice: that human development is "dialectical," with growth occurring through internalized "opposition," and that it advances through a cycle of stages. Directly applying clinical categories to biographical subjects, however, was unavoidably presentist, as it subjected texts to concepts "from the outside" rather than moving out from their manifest meaning in particular historical contexts. In his hands, psychological theory is more than a prompter but less than a map to conclusions. He finds in it questions that open new possibilities for recovering the historical meaning of texts.

As theoretically innovative as his understanding of Marx is, his premise is fundamentally historicist. I use this now oversaturated term simply to denote an understanding of the thought of individuals and groups in the symbolic and normative terms of their time and place. The actual recovery of the psychological 
must work through the ideational and linguistic resources with which the subject, within a psychic structure of conflictual coherence, experienced his inner conflicts and construed his self-understanding. That strategy guided Seigel's reading of the young Marx's dissertation on Democritus, his initial conversion to and eventual (apparent) rejection of Hegel, his engagement with Feuerbach, and the recurring Hegelianism of his post-1848 years. In following the psychological logic of Marx's use of Hegel's concepts of the life cycle and alienation (with its dialectic of pure rationality and madness), and above all of his failed efforts to apply or throw off the Hegelian idea of inversion, Seigel was historicizing psychological biography, even as he sought a historical way to psychologize intellectual biography.

Seigel is at his boldest explaining why Marx failed to finish Capital, though he had more than fifteen years to do so after the publication of the first volume in 1867. Bringing new questions to Marx's often anguished correspondence with Friedrich Engels and others, he provides a deeply researched inventory of Marx's afflictions from the 1850 s to his death in 1883 , from hemorrhoids and boils to bouts of depression. Likewise, he documents in meticulous detail Marx's guilt about keeping the wife and daughters he deeply loved in precarious hardships-not abject poverty, he notes, but always threatening to deprive them of the minimum of bourgeois respectability - by limiting his paid work to intermittent journalism as he struggled to finish the great project. Marx was caught in a vicious circle of obsessive work, and in that sense his illnesses were "self-inflicted." It was the very self-punishment exacted by his work obsession that prevented him from completing the work $(M F, 387)$. Seigel is not simply arguing that Marx failed to finish Capital because he was not physically up to the task. At one level, he faced an intellectual dilemma: the pull between his irremovable Hegelian inclination to abstract theory and his never-finished quest for unassailable empirical proof. Clinging to the theory, he worked obsessively, and in vain, to ground it in facts. What is remarkable is Seigel's effort to demonstrate that structural affinities made this dilemma and Marx's lived experience a psychic whole, a subjectivity united by the relentless conflicting pulls of idealism and materialism. The inability to finish Capital was due to the underlying psychic block that had marked his entire life and thought since he had been caught between his impulse to inner freedom through pure intellection and his father's loving insistence that he fully engage material reality by practicing a bourgeois profession and living a healthy life. It was in that sense that Marx's life had "all the character and dimensions of tragedy" (MF, 388).

"Structural affinity" is my phrase, as is "conflictual coherence." I use it to designate not merely a relation of influence, as when we say that Marx was influenced by Hegel, but correspondences pointing to an originary psychic structure. Seigel identifies structural affinities in this strong sense between life stages, between texts, and between texts and lived experience. Usually the 
procedure entails a precise text-to-text comparison between what Marx wrote and what he clearly absorbed from reading others' texts. There are times, though, when readers may find themselves being asked to accept longer inferential leaps. In a letter to his father in 1837 justifying his conversion to Hegelianism, Seigel argues, concepts of the life cycle and alienation in Hegel's Encyclopedia of the Philosophical Sciences shaped the young Marx's struggle to understand himself. Just as Hegel had drawn these ideas from his own identity crisis, now Marx used them to conceptualize the tug of war between idealism and materialism in himself. But, as Seigel notes, the strongest textual evidence that the young Marx read the Encyclopedia comes much later, in a letter to Engels in 1869 in which he copied out several paragraphs of the book $(M F, 35-6)$. In the context of Seigel's larger textual mapping of Marx's maturation, the inference becomes a thoughtful claim to probability. That is the virtue of Seigel's historicism; it reconstructs a world of shared cultural (and linguistic) resources in which such connections make sense.

It may be useful here, in clarifying Seigel's concept of a life fate and shape, to distinguish between teleological determinism in the strict sense and a psychologically driven trajectory. There is no doubt that in Marx's Fate Seigel argues unswervingly for the latter. At the same time, though, he avoids teleology for the simple reason that in Marx's Fate, as in most of his later biographical works, there is no telos, but a life of tension-ridden choices imposed by an underlying unresolvable conflict. Though the perceptions of choice are formed within this trajectory of irremovable tensions, Seigel is careful not to read texts as signposts to later ones. Within "the whole pattern of Marx's life," the Paris Manuscripts of 1844 can be said to "foreshadow" the Communist Manifesto of 1848 , but "the immediate perception of human nature through the senses-and without any help from philosophy - was still reserved for the future" $(M F, 126-31)$. The larger point is the need to respect the integrity of each text, to take it on its own terms.

Arguably while giving the entire life fate a shape in the sense that I have argued, Seigel also opens spaces for contingencies in the psychological trajectory as it passes through variations over the course of a lifetime. The question-it cannot be resolved here-is whether in the end the two approaches are compatible. That the variations cannot break out of the patterned shape is preordained from childhood or youth; the sources may limit our ability to see how early the initial shaping occurs. I am instinctively at once receptive to and dubious about this premise that the adult cannot escape the formative inner conflicts of the child or the youth. What eases my doubt is that, within his larger explanatory framework, Seigel's interpretive procedure is so flexible, so careful in preserving the integrity of each text, and so attuned to what makes each variation in the patterned shape different from the others, that it cannot be called deterministic in any strict sense. In the close textual work a structural affinity becomes more a 
correspondence than a causal relationship. Seigel asks us to read the existence of a bedrock structure of tension from these correspondences, though he knows very well that one might object that such a reading is arbitrary. There is an element of controlled audacity in his method, at once assuring in its rigorous empiricism and unsettling in the ways it tries to remove the historical imagination from its disciplinary restraints. That is what makes his lives so replete with questions that keep other possibilities open as they seek closure.

\section{$* * *$}

Seigel aimed Bohemian Paris, published in 1986, at a wider audience than Marx's Fate, putting to full use his gift for engaging narrative that draws the reader into the quizzical biographical details of a plethora of idiosyncratic personas in the nineteenth-century Parisian social and cultural space called Bohemia. He succeeded: the book has been a best seller well beyond academe. Nonetheless there are strong continuities between the earlier and later books. His biographical approach remains committed to fusing a psychological (as opposed to psychoanalytical) perspective with a strong social dimension. He is still exploring the conflicted symbioses that lie obscured under simplistic binaries between bourgeois and antibourgeois. The work compulsion, the bourgeois work ethic carried to an ascetic extreme, still figures large.

But in Bohemian Paris Seigel pursues his fascination with bourgeois life from a different angle, asking what the lives of an array of subjects tell us about bourgeois culture, both in its conventional guises and in the partly distorted mirror image of it that was "Bohemia." The shapes of the lives have been drawn to demonstrate the internal tensions of Bohemian culture and the bourgeois culture of which it remained an integral part, testing its boundaries from its borderlands, often by carrying to extremes the very impulses that defined bourgeois identity. The focus is on the conflictual unity of this larger culture, reflected in individual lives. Now structural affinities are more synchronic, across an apparent cultural divide, than diachronic, through the course of a life. A Bohemian fate is not primarily something permanently shaped or determined in childhood or youth; for many, Bohemia was a transitional experience, or a liminal one.

Thirteen years earlier T. J. Clark's Image of the People: Gustave Courbet and the 1848 Revolution had appeared, and Seigel had it clearly in his sights as he wrote Bohemian Paris. As Seigel read him, Clark argues for a misleading distinction between Courbet's "genuine Bohemia," engaged in antibourgeois political activism, and "the corrupted form" of "sentimentalized" Bohemianism that accepted bourgeois life. "Such a view," Seigel wrote, "mistakes a division that existed within individuals, and which was often shifting and uncertain, for a firm distinction between one group and others" $(B P, 404)$. Seigel was particularly 
unhappy with Clark's "Marxist schema," but the larger problem lay in the very way of thinking in a historical sociology of art and literature. He was, I think, right to conclude that, for Bohemia, sociological categories and divisions simply could not do the job. Preoccupied with divisions between social blocks, they had hardly any room for the conflictual coherence of the individual. Only a biographically based "cultural history," intertwining the subjectivity to be found in texts with the subjectivity to be read from the external life course, the "shape" of a life, could capture the ambivalence at the heart of Bohemianism.

The overarching theme of Bohemian Paris is a structural affinity between the "ambivalence" on both sides of the boundary between Bohemia and bourgeoisie. Readers may have reason to regret a certain imbalance; there is hardly any biographical documentation from the bourgeois side. In keeping with his larger argument that the two worlds formed a conflicted but unitary whole, conventional bourgeois life appears in the mirror of itself, at once distorted and hyper-focused, on the Bohemian side. But again Seigel's psychological biography is grounded in a social logic. Most Bohemians were of bourgeois origins, and it is quite likely that the ambivalence toward bourgeois life that pervades their literary and artistic work points to the tensions lurking beneath the unruffled surface of respectability in bourgeois culture. Bohemians were neither bourgeois playing at being Bohemian nor antibourgeois. This is where biographies become crucial to the project. Appropriately, in view of his dissent from Clark, the first extended biography is of Henry Murger, whose Scenes of Bohemian Life, published in 1845 and 1846 , became a popular vaudeville musical in 1849. Contra Clark, Murger did not simply sentimentalize Bohemia for bourgeois consumption, though he did try to dissociate it from political radicalism on the one side and criminality on the other. We learn of Murger's mutable relationship with a group of young men who styled themselves the Water Drinkers and lived a life of ascetic devotion to work in the service of art. Like Murger, the Water Drinkers came from "the lower reaches of the middle class," who were-and here is an example of Seigel's social precision- "poor but respectable, accustomed to material deprivation but not to manual labor, excluded from the comfortable bourgeoisie but, like it, independent and individualistic, insisting on the necessity of restraint and hard work" $(B P, 54)$. Seigel may come closest to a direct application of twentiethcentury psychological theory (but not clinical categories) when he describes the Water Drinkers as adolescents "questioning their parents' actual lives against a purified version of the values supposed to underpin them" $(B P, 56)$. We find the same exaggerated work ethic intermittently in Murger's life, and in some of his stories about Bohemia.

There are obvious risks here. Seigel opens himself to the charge of using psychology to deflate the ideas that moved rebellion, thus giving an ideologically loaded nod of approval to conventional bourgeois society and culture, for all 
its exploitative relationships, bigotries, and hypocrisies. And again the issue of determinism rears its head; as Seigel portrays them, Murger and many other figures were fated to move back and forth-psychologically, and sometimes in way of life-between the bourgeois interior and its borderland. It is central to Seigel's achievement, however, that in the lives of his most significant characters, there is powerful agency in this fatalism; painters and writers find ways to resolve their psychic tensions at the level of artistic strategy, with Bohemian life becoming an art of self-dramatization that allows them to create a public audience without artistic compromise. Seigel's first example is, not surprisingly, Gustave Courbet, one of the founders of artistic modernism, who positions him to launch a frontal attack on Clark's sociological approach. In his self-portraits, Courbet "moves from elegant and dandyish to increasingly ragged and débraillé [disheveled]" ( $B P$, 85 ). He defies bourgeois Paris by playing the role of vulgarian outsider. On the whole, his style of realism allows him to identify with his rural lower-middle-class origins while becoming a denizen of Paris, and to develop the defiant individuality that he considered the wellspring of creativity. With this reading of Courbet, Seigel launches a theme that will run through the rest of the book: the frictional but often paradoxically hand-in-glove relationship between the artistic creativity of the rebellious and the market forces that drive bourgeois life. Courbet realized that, by self-consciously creating a radical persona, a figure of notoriety, the artist could exploit a bourgeois market fascinated with the conflicting impulses internal to it. Again, the overarching concept is one of conflictual unity within the individual's psyche, not conflict between classes. It makes notoriety at once rebellious and marketable.

Bohemian Paris has far more biographies of iconoclastic characters than can be recounted here. I would be remiss, though, if I did not recommend Seigel's sketch of the composer Eric Satie, who he sees assimilating Bohemian elements to an emerging avant-garde. The great enemy of the ponderous and the overblown in nineteenth-century music, Satie created "furniture music" and other commercial inventions while scorning commerce. He made his small room (which no one visited) the headquarters of a "Metropolitan Art Church of Jesus the Conductor" (of which the only member among the claimed ten million was himself); he only ate white foods; he kept a precise daily schedule, receiving inspiration from 10:23 to 11:47 am and again from 3:12 to 4:07 pm; he titled one of his works Three Flaccid Pieces (for a Dog) and another Bureaucratic Sonata. Seigel obviously takes great pleasure in teasing meaning out of Satie's self-fabrications, as he hides himself, playfully mocks himself, and jabs at the stereotypical bourgeois; and the reader will too.

While there is something playful about Seigel's portrait of Satie, he paints Charles Baudelaire as the hero of the story. As Thomas Ort has emphasized in another essay in this forum, what makes Baudelaire the heroic figure of Bohemian 
Paris is that his capacity for intense self-concentration, for the work ethic so many Bohemians disdained, transformed the seemingly undisciplined diffusion of his life experiences - his inclination to aristocratic dandyism, the counterpull of the "messy, slovenly" world of Bohemia, his squandering of his inheritance, his sexual dissipation, the experiments with drugs - into art. Here again we see Seigel's gift for finding creative agency in the fated shape of a life. Precisely because his subject is Baudelaire's creativity, Seigel refuses to reduce him to a clinical category; "to invoke the psychological language of masochism would be to cloud over the element of conscious and determined exploration in Baudelaire's Bohemianism" $(B P, 98)$. His determination cannot be characterized simply as antibourgeois. In 1848 , Baudelaire was with the rebels on the barricades, but "his political notions were neither clearheaded nor stable, mixing conservative sentiments with radical impulses in a murky but heady brew" $(B P, 106)$. Nor was he a bourgeois manqué. The structural affinity here lies in the tension between work and indulgence on both sides of the bourgeois/Bohemian divide. In the end, Baudelaire was, despite himself, a Bohemian writ large, and perhaps more than any other figure he realized the creative power of Bohemian culture. There is no better example of Seigel's deft historical imagination than this biographical portrait.

When Bohemian Paris appeared in 1986, Seigel had unfinished business. Part Three examines the transition from Bohemia to the twentieth-century avant-garde, and Marcel Duchamp serves briefly as "a paradigmatic avant-garde figure" $(B P, 389)$. In the biography titled The Private Worlds of Marcel Duchamp, published in 1995, Seigel ponders more deeply the shift Duchamp represents. To do so, he has to make sense of some of the most enigmatic objects in twentiethcentury art: the cubist-like Nude Descending a Staircase (only the title makes apparent that the image is of a nude woman), whose inclusion in the Armory Show in New York in 1913 quite suddenly lifted him to celebrity; the "readymades" (among them a coat rack, a bottle rack, a shovel, and a urinal), in which the artist's function is no longer to create something unique in substance and form from an inner vison, however camouflaged, but to make the artist's interiority completely unreachable by displaying ordinary utilitarian objects produced by modern industry; and Boxes in a Suitcase, a project that was at once a kind of self-concealment in a private symbolic universe and a commercial venture, which he worked on intermittently for thirty years until his death in 1968.

Why would an intellectual and cultural historian devote a book to deciphering such a purposely undecipherable figure? Seigel's reading of Duchamp has a double effect: issuing a warning about impulses in the modernist experience from Bohemia onward, and at the same time building an instructive contrast, throwing modernism's positive significance into bolder relief. The avant-garde "belongs to our culture ... and never more wholly and loyally than in its claims to be ... its destroyer and grave digger, for modern Western culture is the first to 
be nurtured and thrive on opposition and negation" $(P W, 15)$. But "what would art become," he asks, "at the point where modernist subjectivity was pushed to its limits, stretching the bridge between artist and beholder until it broke?" $(P W, 53)$. In Duchamp's art, the bridge broke. To switch metaphors, Seigel found in it the erasure of a thin and wavering line; the subjectivity of uninhibited individuality became hermetic privatism.

This theme may make Private Worlds Seigel's signature book, the one that more than any of the others shows the combination of absorption and alarm that has marked his engagement with modernism over his entire career. The fact-already apparent in Bohemian Paris - is that Seigel finds historical progress in modern bourgeois society and culture considered over the long view. ${ }^{4}$ At the heart of the bourgeois phenomenon lay a commitment to a new, subjective individualism, an opening of spaces of "individual liberation" in the absence of the transcendent authority once offered by traditions. Such spaces made possible an unprecedented social and cultural pluralism, thanks in part to symbioses with Bohemian and avant-garde dissent. Seigel also finds it right and proper that bourgeois life, though lured to indulgence, nonetheless kept its center of gravity in the work discipline he himself has practiced, and that he finds essential to turning the conflictual coherence of individual subjectivity into "controlled and practiced images" that engage-and often unsettle-the beholder $(P W, 218)$.

Bourgeois society has surely created a legal order unprecedented in its allowance of openness, but one does not have to be a Marxist, or a disciple of Herbert Marcuse, or a Foucauldian to ask how capable it really is of self-critique. Inadvertently, Seigel largely passes over the fact that in capitalist modernity the market absorbs or coopts so much dissent, making itself deaf to critique as it seems to be listening. Likewise individualism surely has been a linchpin of bourgeois liberal ideology, but that principle, particularly as it operates as an ideological conceit for individual success, can hide the extent of conformism that bourgeois commercialism and work life demands. Hence some readers may find Seigel's notion of bourgeois progress less an assertion of historical fact than an act of faith. If this is faith, however, it does not prevent Seigel from practicing, once again, the imaginative historicism that has marked his work from the start. He describes the book as "only mildly and partially psychobiographical" $(P W$, 14). There may be more material on Duchamp's childhood and boyhood than on Marx's, but not enough to draw conclusions. Did some of Duchamp's art express his resentment of his younger sisters for usurping his mother? Did his fantasy of incest with one of the sisters become a central theme of his work? Probably not, and in any case there is no way of knowing. All that is evident - and this is

4 Jay Tolson, "Flirting with Freedom," The Nation, 5 April 1986, 492-6. 
critical to Seigel's overall interpretation-is that Duchamp was inclined to a cult of mystery about himself. What is striking is how Seigel wends his way between a dismissive intolerance of psychological theories and a naive embrace of them. He devotes space to such theories, he tells the reader whose patience may be wearing thin, because they open out the multiple possible reactions the artist might have wanted to effect, and because the reader should be aware of possible interpretations he himself has decided not to pursue $(P W, 60)$. It is a gesture of open-mindedness, admirable but in the end assuring the reader of Seigel's own historicist (and empirical) rectitude.

And yet in Private Lives the analysis is, at bottom, no less psychological than in his previous books. Seigel continues to find a conflictual coherence-what he calls "a core of psychological coherence" $(P W, 14)$-in his subject's psyche, and a structural affinity between his art and the way he lived his life. The conflict is between an impulse to connectedness and an impulse to detachment, with the latter increasingly dominant. The success of Nude Descending a Staircase made Duchamp "feel he had somehow disappeared behind his work" $(P W, 9)$. With Boxes in a Suitcase Duchamp brings his effort to dissolve "his own subjectivity as an artist" to an endpoint $(P W, 12)$. The endpoint, Seigel argues, is a selfdelusion; what seems to be a dissolution of personal subjectivity is in fact a radical assertion of the person, now apparently free of the inner conflict that had fueled his earlier career. This reading of Duchamp makes Private Lives in one way critically different from Seigel's earlier books. The difference lies in the denouement of the psychological plot, and it is essential to his warning about an avant-garde art turned entirely in on itself. As Baudelaire conceived it, selfvaporization was a preparation for the labor of artistic creation. Like Marx, he could not cast off the burden of indwelling social and cultural contradictions, and that is precisely why his art could have public resonance in his society and culture. Duchamp did resolve his inner tension, by settling at one of its poles. It is no accident that, in sharp contrast to Baudelaire, he never had the compulsion to work, and that his "one great passion" was chess as a self-referential game.

In a fascinating discussion of artistic "style," Seigel uses the counterexample of Picasso to argue that Duchamp's resolution of inner conflict precludes the development of a style, "a way of representing a highly personal encounter with the world so that others can participate in it without losing their bearings" $(P W, 237)$. This is not, I should stress, a philistine dismissal of avant-garde art because it is not sufficiently representational. Nor is it a roundabout way of saying "even I could have done better than that." To Seigel, the difference lies between a radicalization of bourgeois individualism that can offer it transformational sources for renewal, and an illusory effacing of individualism, a denial of the personal that in its extreme forms - and here is the disquieting irony - makes the 
personal so private, so deeply sequestered, and so thickly veiled as to renounce any public connection.

In the progression of Seigel's work from Marx's Fate to Private Worlds, we see what makes him such an important contributor to the theory and practice of intellectual history. He has used a biographical approach to integrate psychological inquiry into a contextual understanding of historical meaning. He has argued for a coherent subject not by positing some sort of unproblematic unity beneath swirls of confusion, but by placing at the center of things, as the nexus between life, cultural creation, and historical processes, the internalized oppositions of modern subjectivity that shape lives. It is this conflictual coherence, he argues, that opens a space for agency within the determinative forces of psychological fate. In biographies centered on that space for creativity and critical defiance, historians reflect on their own agency and its limits in relation to the historical process.

\section{$* * *$}

It is perhaps obvious by now that the personal roots of Seigel's own work and his use of it to take a stand on issues of cultural politics are inseparable. In the introduction to Marx's Fate, he tells us that the Eriksonian-Hegelian model he adopted was shaped in part by his "having undergone an evolution that seem [ed] to combine consistency and discontinuity in [his] own life" $(M F, 9)$. He did come to terms with Marx, granting the enduring value of many of his insights, but portraying his life as a tragic failure, both in the way he tried to live it and, inseparably, in his theoretical ambitions. That conclusion has been a precondition of Seigel's commitment to the broadly liberal values of an open and pluralistic society and culture that inform his work on the political implications of modernism. The avant-garde is "never more wholly and loyally [a part of modern culture] than in its claims to be in revolt against it, to be its destroyer and grave digger, for modern Western culture is the first to be nurtured and thrive on opposition and negation" $(P W, 15)$. In Duchamp he found an avant-garde trend that might end the modernist contribution to a civic culture renewing itself through its engagement with its distorted but by no means aimless alter ego.

With his recent Between Cultures: Europe and Its Others in Five Exemplary Lives, Seigel enters more explicitly the field of argument that has formed around the concept of the global. Coming as it does from a historian who has spent most of his career studying Europe, Between Cultures is a remarkably global book. The aptness of the title is apparent from the book's five figures, to each of whom a chapter is devoted. The three Westerners-Richard Burton, T. E. Lawrence, and Louis Massignon-injected themselves into non-European ways of life. The two non-Westerners-Chinua Achebe and Orhan Pamuk-wrestled 
with a European culture that both attracted and repelled them. Perhaps the least known is Massignon, who spent most of his adult life as a scholar of Islam and theorist of history at the Collège de France. In 1908, while on an archaeological expedition in the Middle East, he had thrown off the youthful skepticism and anticlericalism he had inherited from his father for a "fervent and exacting" Catholicism. His fascination with the Muslim mysticism of Husayn Ibn Mansur al-Hallaj, which he knew to be at odds with his beliefs, fueled his own Christian mysticism.

Seigel knows he is navigating an ideological minefield. He makes it clear that he is not quarreling with the current rejection, particularly in postcolonialist thought, of the Eurocentrism of the "West-and-the-rest" dichotomy. He asks readers to distinguish, though, between the need to correct the distortions perpetuated in a Eurocentric discourse of an East-West polarity and the need to understand that discourse historically as a "phenomenon of our modern world history." The fact is that to all his figures the polarity was an experiential reality. $\mathrm{He}$ is by no means denying that on moral grounds imperial power wrought terrible damage on subject peoples. But if, in the cases of Burton, Lawrence, and Massignon, we dwell exclusively on their involvement in that power and the discourses of domination that justified it, we miss the fact that they went remarkably far in penetrating (and living) non-Western ways of life and were quite forthright in correcting Western self-serving stereotypes about them. From the other direction, Achebe was highly critical of what he considered the barbarisms of Ibo life, even as he blamed the West for destroying what was valuable about it. This is not cultural relativism in the unqualified sense, the essentialism that denies any outsider the right to find fault with any culture. Seigel believes that no culture should be exempt from critique, from within and from without. That, of course, opens Between Cultures to the charge of being Eurocentric despite itself.

In the end, what Seigel finds so "exemplary" about each of his chosen figures is not simply that living with-or, perhaps better, in - a contrast between cultures made him critical of his own, or of the other, or of both. "Intercultural existence" gave them a deeper skepticism about the claims that any human culture makes to provide all the meaning a person needs. The most puzzling (and controversial) case in point is Burton, who, despite his deep involvement in British imperial rule and his occasional racist language about Jews and Africans, conducted an "all-out assault ... on every particular culture's claims for the special validity of its intellectual and moral constructions" $(B C, 239)$. Seigel draws the same implications from the novels of Achebe and Pamuk. The foundational premise-the one his readings are meant to demonstrate empirically-is what he conceives to be a human capacity for an analytical and interpretive "reflective independence" (perhaps dormant in most people) that is never fulfilled, but never abandoned in an uncritical embrace of one culture $(B C, 8)$. His obvious 
target is any unequivocally essentialist concept of selfhood and identity, though he avoids the term "identity politics." Put simply, in their insistence on a single and exclusive identity, ideologies meant to liberate groups can preclude the individual liberation that modernity in principle makes possible. The "between" of Seigel's title is meant to emphasize that none of his protagonists was fully integrated into either the culture he was born into or the one he entered. It is not meant to imply that they occupied a cultural space in-between. Rather, they lived simultaneously, if uneasily and even in agony, in two cultures-and that they could do so is precisely the point Seigel wants to make in response to the more extreme advocates of identity politics. Even when you disguise yourself to enter into another culture-as Burton and, to a lesser extent, Lawrence did-you remain the same person. Distancing yourself from your own culture, you also remain distanced from the other. With the shift from a single French culture, at once bourgeois and Bohemian, to encounters between vastly different cultures, the concept of structural affinity loses its relevance. The polarities of conflictual coherence are so different that reflective independence emerges from an irremovable "split," "a dialogue between two personae within a single self" $(B C, 2)$ who are self-conscious adversaries. And yet, as painful as this degree of inner conflict is, it is coherent enough to be critical in its creativity.

As in Seigel's earlier work, psychological biography is essential to conveying this conflictual coherence. He provides multilayered readings of, among other sources, autobiographies, memoirs, correspondence, and fiction. The chapter on Lawrence is a hermeneutic tour de force, an unraveling of the densely tangled psyche laid bare in The Seven Pillars of Wisdom. Very early in the chapter the reader wants to know about the family dynamic of Lawrence's childhood and youth, but Seigel holds that to the end, seeming to tease the reader. Characteristically, he treads cautiously.

\section{$* * *$}

In Between Cultures Seigel's term of use for "reflective independence" shifts from individualism to individuality. In the global context, individualism is too provincial and indeed Eurocentric, evoking a specifically European bourgeois culture. I suspect, though, that with the term "individuality," Seigel also wanted to ground his universal point about cultures and individuals in a specifically European humanist tradition that dates back to the Renaissance (his original field of study) and found perhaps its fullest expression in German neo-humanism. There is an irony here. As Seigel is fully aware, the modernity to which Wilhelm von Humboldt and Friedrich Schiller were reacting in the 1790 s was quite different from the modernity in which Seigel's biographical subjects had to find ways to live and realize their creativity. To Humboldt and Schiller, the 
threat of dehumanization-what seemed to be a process in which individual subjects were being deprived of even a measure of autonomy-lay in the stifling routinism of state bureaucracies and the tunnel-visioning required by an increasingly complex modern division of labor. They imagined the fully human refracted in a personality of harmoniously integrated powers. In the course of the nineteenth century, and with greater impetus in our Freudian and post-Freudian ages, personality takes the form of a conflictual coherence of the subject, which is often self-lacerating, even self-ravaging, but, Seigel insists, is the condition of the creativity that renews culture. This approach to biography gives it a deep psychological dimension, but the individual psyche can only be understood as an impress-a unique impress—of cultural and social lesions. It is this idea of contextual impress, though it sets its own parameters for creative agency, that keeps Seigel's biographical work at a safe distance from a fatalist psychological reductionism. One suspects that, as Seigel hinted in Marx's Fate, there is something autobiographical about all this-that it points us to a conflictual coherence that Seigel himself has lived and turns to remarkably creative uses as a historian. He ends Between Cultures with a statement of belief that his chosen cases provide "testimony ... to the broad human capacity for maintaining a liberating distance from the ways of life that form us" $(B C, 245)$. Seigel's historical method and his own inner contentions have nourished each other. 